\title{
Field Comparison of Two Sampling Methods for Triglycidyl Isocyanurate
}

\author{
Steven M. Thygerson", Joshua H. West, Ray M. Merrill \\ Brigham Young University, Provo, USA \\ Email: *steven.thygerson@byu.edu
}

Received November 13, 2013; revised December 13, 2013; accepted December 20, 2013

Copyright (c) 2013 Steven M. Thygerson et al. This is an open access article distributed under the Creative Commons Attribution License, which permits unrestricted use, distribution, and reproduction in any medium, provided the original work is properly cited.

\begin{abstract}
Side-by-side field sampling comparisons for Triglycidylisocyanurate (TGIC) were conducted using 1) a laboratory method to determine specific levels of airborne TGIC, and 2) the NIOSH 0500 method for Particulates Not Otherwise Regulated for total aerosol mass. Resulting concentrations from the NIOSH 0500 method in conjunction with the powder coating manufacturer safety data sheet are then used to estimate TGIC levels in air. This second method is designed as a simpler and less expensive sampling and analytical method. Results show that the NIOSH 0500 method resulted in airborne concentrations up to ten times greater than the laboratory method resulting in specific for TGIC. Coefficients of variation show that the laboratory method had the least variability. We conclude that the NIOSH 0500 method and subsequent calculation should not be used to quantify TGIC levels in powder coatings. However, this method may be used to monitor effectiveness of exposure control.
\end{abstract}

Keywords: Triglycidylisocyanurate; Air Sampling; Field Comparison

\section{Introduction}

Triglycidylisocyanurate (TGIC, CAS no. 2451-62-9) is used extensively as a curing agent in polyester powder coatings. Workers are exposed during the manufacture and use of TGIC. There are documented human cases of contact dermatitis and sensitization [1-3]. Inhalation exposures should be expected since powder coatings containing TGIC are applied by electrostatic spraying. Inhalation exposure to these powder coatings increases the risk of occupational asthma (hypersensitivity pneumonitis) $[4,5]$.

Industrial hygienists for the Occupational Safety and Health Administration (OSHA) have documented obstacles when conducting TGIC air sampling for OSHA compliance purposes [6]. To overcome these obstacles, industrial hygienists should consider the various TGIC air sampling methods and subsequent interpretation based on existing occupational exposure limits. Current air sampling methods collect airborne particulates into filter media and use either liquid chromatography or gas chromatography to determine concentrations of airborne TGIC in powder coatings $[7,8]$. While direct comparisons can then be made to occupational exposure limits,

"Corresponding author. these methods are more time-consuming and expensive compared to other dust sampling methods.

An estimate of exposure to TGIC in powder coatings has been suggested and may also be a valid measurement technique [9]. This is done by sampling for total inhalable particulate (total aerosol mass) and then estimating how much of the material on the filter would be TGIC. The safety data sheet (SDS) for the powder coating should be used to determine the percent of TGIC in the powder. While sampling and analysis using a specific laboratory method for TGIC will quantify airborne exposure and is considered the gold standard, using the total aerosol mass method and subsequent calculation may result in valid estimates of worker exposure to TGIC. These estimations would be a less time-consuming and less costly method for determining TGIC exposure. Therefore, the purpose of this study is to determine if field sampling for total inhalable particulate and subsequent calculation based on MSDS information provides a valid field estimate of TGIC exposure in the electrostatic spraying of powder coatings.

\section{Methods}

This study compares field concentration measurements 
based on two sampling methods for TGIC in air. The first (Method 1) is a laboratory method using gas chromatography and mass spectrometry (GC/MS) to directly measure the amount of free TGIC on a Teflon filter [7]. Sampling times ranged from 60 to 65 minutes with a flow rate of 1.8 liters per minute. The average sampling volume was 110.7 liters. The analytical detection limit was $0.68 \mu \mathrm{g} / \mathrm{m}^{3}$. The filter media was Teflon with PTFE support, 25 mm (SKC Cat\# 225-1708) SKC cassette filter assembly (SKC Cat\# 225-ZT). The samples were analyzed by gas chromatography with mass spectrometric detection. This method allows employers to conduct air monitoring and make direct comparisons to the occupational exposure limits for TGIC.

The second method (Method 2) was developed as an estimate or screening of exposure levels by using the NIOSH Sampling and Analytical Method 0500 for total aerosol mass of Particulates Not Otherwise Regulated (PNOR) [10]. The sampling flow rate was calibrated at 1.8 liters per minute. Sampling times ranged from 60 to 65 minutes for an average volume of 111.7 liters. This method measures total aerosol mass (i.e. the total weight of dust collected on the filter) and subsequent calculation estimates how much of TGIC was captured on the filter. The safety data sheet (SDS) provided by the powder coating manufacturer must be consulted to determine the percent TGIC in the coating powder. The equation below was used to estimate the concentration of TGIC based on results of the total inhalable particulate sampling.

$$
C_{\text {TGIG }}=\left(C_{\text {TotalParticulate }} \times \% \text { TGIC }\right)
$$

Under section II (Hazardous Ingredients/Identify Information) of the manufacturer SDS, TGIC is normally listed as containing less than $5 \%$ TGIC or greater than $5 \%$ but less than $10 \%$. For example, if the analytical results of total inhalable particulate reports a concentration below $1 \mathrm{mg} / \mathrm{m}^{3}$ (8-hr time-weighted average) and consultation with the SDS show TGIC concentration in the powder coating a $10 \%$, the resulting estimated exposure for TGIC is calculated to be $0.1 \mathrm{mg} / \mathrm{m}^{3}$ (i.e., $10 \%$ of $1=$ $0.1)$.

TGIC sampling was performed in the field at a manufacturing site using electrostatic powder coating techniques. This site coated products in a powder coating room approximately $6 \mathrm{ft}$. by $30 \mathrm{ft}$. The powder coating room is in a larger room isolated from other product lines and is held in negative pressure in relation to the larger room using floor sweep ventilation. Significant amounts of overspray are produced in this process. In this particular coating room, all overspray of the powder is captured by the floor sweeps. Side-by-side TGIC sampling was conducted by positioning the Teflon filter (Method 1) and the PVC filter (Method 2) three inches apart with their inlets 24 inches above the floor of powder coating room. The filter inlets were 6 inches above the floor sweeps. This location guaranteed high concentrations of dust and subsequent TGIC concentrations on the filter. The same powder coating product was used for each of the sampling runs. All sampling runs were conducted at approximately the same time each day to ensure continuous spraying inside the powder coating room. The MSDS for the powder coating product revealed that it contained $5 \%$ to $10 \%$ TGIC. For the purposes of this study, $10 \%$ TGIC was used in the calculation.

For each sampling run, the strategy was to have four pumps running, two for the Method 1 and two for the Method 2. This would have resulted in 36 total samples. However, it was determined that one sample using Method 1 would suffice for comparison to one sample of Method 2 if run side-by-side. Therefore, sampling took place during 11 separate sampling runs resulting in 11 samples for each method. Each sampling run occurred on different days. Sampling runs occurred at the beginning of the shift when the powder coating room was clean. The coefficient of variation was used to obtain an estimate of variation that is relative to the size of the mean. Spearman's rank order correlation was used to determine the degree of correlation between the two methods.

\section{Results}

Results for each side-by-side sampling run are shown in Table 1. The calculation from Figure 1 was applied to the sampling results of Method 2. The results were up to ten times greater than the sampling results using Method 1. Relative variation for the two methods is shown in Table 2. For Method 1 the CV was higher than Method 2 ( 0.78 compared to 0.45 , respectively). There was no significant correlation between the two methods (Spear-

Table 1. TGIC sampling results for each sampling run.

\begin{tabular}{ccc}
\hline Sampling Run & $\begin{array}{c}\text { Method } 1 \\
\text { results }\left(\mathrm{mg} / \mathrm{m}^{3}\right)\end{array}$ & $\begin{array}{c}\text { Method 2 results after Figure } \\
\mathbf{1} \text { calculation }\left(\mathrm{mg} / \mathrm{m}^{3}\right)\end{array}$ \\
\hline Run 1 & 0.38 & 3.1 \\
Run 2 & 0.055 & 0.79 \\
Run 3 & 0.49 & 2.8 \\
Run 4 & 0.35 & 3.5 \\
Run 5 & 0.077 & 4.2 \\
Run 6 & 0.31 & 4.7 \\
Run 7 & 0.91 & 5.2 \\
Run 8 & 0.60 & 1.5 \\
Run 9 & 0.12 & 3.8 \\
Run 10 & 0.17 & 1.4 \\
Run 11 & 0.16 & 2.8 \\
\hline
\end{tabular}


Table 2. Relative variation of TGIC sampling methods.

\begin{tabular}{ccccc}
\hline Sampling Method & Range $\left(\mathrm{mg} / \mathrm{m}^{3}\right)$ & Mean $\left(\mathrm{mg} / \mathrm{m}^{3}\right)$ & SD & CV \\
\hline Ciba-Geigy (Method 1) & $0.6-0.91$ & 0.33 & 0.26 & 0.78 \\
$\begin{array}{c}\text { NIOSH 0500 with } \\
\text { calculation (Method 2) }\end{array}$ & $0.8-5.2$ & 3.1 & 1.4 & 0.45 \\
\hline
\end{tabular}

man's Rho $=0.214 ; \mathrm{P}=0.527)$.

\section{Discussion}

Large differences in resulting means occurred between the sampling methods analyzed in this study. Method 2 resulted in larger concentration values. Free TGIC is expected to cross link resulting in analyzed concentrations lower than air concentrations available for worker inhalation. When using Method 2, there is no correction for the cross-linking of free TGIC. This may explain the large differences between the two sampling method results. White [11] discusses problems associated with TGIC "decomposing” on storage. Another method for quantifying TGIC addresses the loss of free TGIC due to storage. This loss is shown to be a factor at lower TGIC concentrations [8]. Both methods resulted in TGIC concentrations that exceeded the occupational exposure level of $0.05 \mathrm{mg} / \mathrm{m}^{3}$. These high concentrations were expected based on the location of the sampling. Therefore, the significant difference between the means of the two sampling methods in this study may not be a result of delayed analysis.

The CVs estimated in this study provide a comparative measure of relative variation for each sampling method. Evaluation of the CVs suggests that Method 2 provides less variability around the mean. However, this does not provide evidence that Method 2 should be selected over Method 1. There was no significant association between the two methods.

Method 2 may provide a relatively inexpensive and simpler method of assessing exposure. However, it will not give the same accuracy as specifically measuring for TGIC using Method 1 or any other TGIC-specific method. It is an estimate only to determine if further exposure controls should be used. Hence, industrial hygienists should not utilize Method 2 as a way to demonstrate compliance. Rather, it could be used as a way to routinely monitor control effectiveness. Initially, both methods could be used side-by-side to demonstrate good standards of control. If results show exposures air concentrations below the occupational exposure levels for both methods, subsequent monitoring could be done using only Method 2. Using Method 2, one may reliably say that if results are low as a result of continuous improvement, then overall TGIC exposure will also be below specified exposure levels.

\section{Conclusions}

Quantifying TGIC exposure using total aerosol mass sampling (NIOSH 0500 sampling method) with subsequent calculation showed significantly higher concentration of TGIC in air than using the Ciba-Geigy method specific for TGIC. TGIC cross-linking may explain the differences between the two method results. Further research is required to determine the amount of free TGIC that cross-links between sampling and analysis. However, to avoid this confusion and to determine the concentration of TGIC in air, a TGIC-specific method should be used.

This study lends support to using Method 2 as an estimate of overall exposure control. It should not be used simply as a cost effective means of determining TGIC exposure in the powder coating industry. Application of a correction factor may allow for more accurate sampling method comparisons and could be studied further. Because of the small sample size in this study, results do not conclusively suggest that Method 2 will provide adequate estimates for TGIC. This result does, however, provide the basis for further investigation. There may be a basis to apply these general principles for the comparison of other sampling methods involving estimates based on the manufacturer SDS.

\section{REFERENCES}

[1] C. G. T. Mathias, "Allergic Contact-Dermatitis from Triglycidylisocyanurate in Polyester Paint Pigments,” Contact Dermatitis, Vol. 19, No. 1, 1998, pp. 67-68. http://dx.doi.org/10.1111/j.1600-0536.1988.tb02877.x

[2] L. Meuleman, A. Goossens, C. Linders, F. Rochette and B. Nemery, "Sensitization to Triglycidylisocyanurate (TGIC) with Cutaneous and Respiratory Manifestations," Allergy, Vol. 54, No. 7, 1999, pp. 752-756. http://dx.doi.org/10.1111/j.1398-9995.1999.00103.x

[3] R. Jolanki, L. Kanerva, T. Estlander and K. Tarvainen, "Concomitant Sensitization to Triglycidylisocyanurate, Diaminodiphenylmethane and 2-Hydroxyethyl Methacrylate from Silk-Screen Printing Coatings in the Manufacture of Circuit Boards," Contact Dermatitis, Vol. 30, No. 1, 1994, pp. 12-15. http://dx.doi.org/10.1111/j.1600-0536.1994.tb00721.x

[4] S. Quirce, M. Fernandez-Nieto, M. de Gorgolas, G. Renedo, J. Carnes and J. Sastre, "Hypersensitivity Pneumonitis Caused by Triglycidylisocyanurate,” Allergy, Vol. 59, No. 10, 2004, pp. 1128-1128. http://dx.doi.org/10.1111/j.1398-9995.2004.00506.x

[5] P. Piirila, T. Estlander, H. Keskinen, R. Jolanki, A. Laakkonen, P. Pfaffli, et al., "Occupational Asthma Caused by Triglycidylisocyanurate (TGIC),” Clinical \& Experimental Allergy, Vol. 27, No. 5, 1997, pp. 510-514. http://dx.doi.org/10.1111/j.1365-2222.1997.tb00738.x

[6] S. Allmaras, "Worker Exposure to 1,3,5-Triglycigyl Isocyanurate (TGIC) in Powder Paint Coating Operations,” 
Applied Occupational and Environmental Hygiene, Vol. 18, No. 3, 2003, pp. 151-153.

http://dx.doi.org/10.1080/10473220301354

[7] C. Geigy, "Analytical Method AV-052.1-Araldite PT 810 Pure and in Powder Coatings,” Basel, Switzerland, 1991.

[8] HSE, "Methods for the Determination of Hazardous Substances-Triglycidyl Isocyanurate (and Coating Powders Containing Isocyanurate) in Air," MDHS 85, Sudbury, 1997.

[9] HSE, "Control of Exposure to Triglycidyl Isocyanurate (TGIC) in Coating Powders,” EIS No. 15 (rev. 2), Sud- bury, 2003.

[10] National Institute for Occupational Safety and Health (NIOSH), "NIOSH Manual of Analytical Methods, 4th ed.,” DHHS Publication 94-113, Cincinnati, OH, NIOSH, 1994.

[11] J. White, "Determination of Triglycidyl Isocyanurate from Powder Coatings in Occupational Hygiene Samples by Gas Chromatography with Mass Spectrometric Detection,” The Annals of Occupational Hygiene, Vol. 48, No. 6, 2004, pp. 555-563.

http://dx.doi.org/10.1093/annhyg/meh046 